\title{
FIVE-YEAR FOLLOW-UP OF IMPLANTS PLACED SIMULTANEOUSLY WITH INFERIOR ALVEOLAR NERVE LATERALISATION OR TRANSPOSITION
}

\author{
Stefan Peev ${ }^{1}$, Borislav Ivanov ${ }^{2}$, Elitsa Sabeva ${ }^{1}$, Tihomir Georgiev ${ }^{3}$ \\ ${ }^{1}$ Department of Periodontology and Dental Implantology, \\ ${ }^{2}$ Department of Clinical Medical Sciences, \\ ${ }^{3}$ Department of Oral and Maxillofacial Surgery, \\ Faculty of Dental Medicine, Medical University of Varna
}

\begin{abstract}
INTRODUCTION: The aim of this investigation was to evaluate the 5-year outcomes regarding presence of intraoperative and postoperative complications and the survival rate of implants placed simultaneously with lower alveolar nerve lateralization or transposition.

MATERIAL AND METHODS: implants placement was performed on 34 patients with advanced atrophy of the posterior mandible simultaneously with lower alveolar nerve lateralization or transposition. Transposition was done only in two cases; in the rest of the cases lateralization of lower alveolar nerve was performed.

RESULTS: The survival rate at the end of the fifth year after implant placement was $100 \%$. The mean height of residual bone at the region of implant placement was $2.76 \mathrm{~mm}$. The mean marginal bone resorption for at the fifth year was $0.309 \mathrm{~mm}$. In $20.6 \%$ of cases a positive BOP (bleeding on probing) was registered. $14.7 \%$ of the patients were free of symptoms of NSD (neuro-sensory dysfunction). In the rest of the patients the mean duration of NSD was 2.06 weeks. In $76.4 \%$ of patients the symptoms of NSD of nervus alveolaris inf. resolved after the second week. The maximum period of reported NSD was 6 weeks. No permanent NSD occurred.
\end{abstract}

CONCLUSION: Properly performed lateralization or transposition of the lower alveolar nerve is associated with minimal risk of permanent neuro-sensory dysfunction and providing an opportunity for placement of intraosseal implants in the posterior mandible with high survival rate.

Keywords: implant, transposition of inferior alveolar nerve, lateralization of inferior alveolar nerve, neuro-sensory dysfunction of inferior alveolar nerve

Address for correspondence:

Stefan Peev

Department of Periodontology and Dental Implantology

Faculty of Dental Medicine

Medical University of Varna

84 Tzar Osvoboditel Blvd.

9000 Varna, Bulgaria

e-mail: stefan.peev@mail.bg

Received: November 30, 2015

Accepted: December 14, 2015

\section{INTRODUCTION}

Lateralization and transposition are methods which change the position of IAN (inferior alveolar nerve), thereby an opportunity is created for implant placement without additional augmentation procedures (1). In lateralization of IAN, an access osteotomy is performed as the neurovascular bundle which is distal to the mental foramen is removed laterally, implants are placed and the neurovascular bundle is 
returned to contact the already set implants. The position of the mental nerve is not changed. By transposition of IAN the position of IAN is changed together with the position of the mental nerve, thereby the connection to the incisal nerve is interrupted (2-4). For the first time the process is described by Alling (5) as a method for treatment of patients with advanced atrophy of the lower jaw where there is expression to a different level of exposure of the mandibular canal and exposure of IAN. For the first time Jenson and Nock (5) described the transposition of IAN for the purpose of implant placement in the posterior mandible. The authors reported disorder in neuro-sensory function of the IAN, which resolved in all patients after five weeks.

\section{MATERIAL AND METHODS}

In 34 cases with advanced atrophy of the posterior mandible we performed implants placement simultaneously with lower alveolar nerve lateralization or transposition. 15 of the patients were men and 19 of them were women. Transposition was performed only in two cases, and at the rest of the cases lateralization of lower alveolar nerve was performed.

Cone-beam computer tomography was used to establish the location and the course of the mandibular canal. The operation was performed under mandibular block or under general anesthesia. After elevation of muco-periosteal flap to access the lateral surface of the body of the lower jaw by using ultrasonic bone-surgery device $10 \mathrm{~mm}$ distal to the foramen mentale a bone plate was cut in the mandibular compact bone, as the bone was cut down until the cancellous bone was reached. The plate had following dimensions: $10-20 \mathrm{~mm}$ length and $5-10 \mathrm{~mm}$ width, roughly. Then the plate was removed and the neurovascular bundle was identified and its mobilization was done by using appropriate instruments. Neurovascular bundle was displaced laterally. If its mobility was considered as insufficient, further extension of the osteotomy was performed in the distal direction. In the cases of transposition the neurovascular bundle was exposed to the mental foramen and its connection to the incisive neurovascular bundle was interrupted. After shifting of the neurovascular bundle in lateral direction an osteotomy for implant placement was performed. After placing the planned implant, collagen fleece was placed between the im- plant and neurovascular bundle, then the neurovascular bundle was released and repositioned. In order to avoid the compression of neurovascular bundle, the bone plate which was removed at the access window was particulated by using Micro Bone Mill (Aesculap) and was returned to the osteotomy defect, as it was covered by the pericardial collagen membrane.

The flap was then repositioned and sutured using 5-0 monofilament suture material. The patients were prescribed an antibiotic and non-steroid antiinflammatory drugs.

The following criteria were recorded:

1. Presence of intraoperative and postoperative complications.

2. Occurrence of Neuro-sensory dysfunction.

3. Survival rate for the period of the study.

4. Presence of bone resorption visible on radiography.

5. Bleeding on probing (established by UNC-15 periodontal probe).

6. Data were processed using SPSS IBM Statistic 19.3.2.3

\section{RESULTS}

The mean age of the patients was 59.21 years. The survival rate at the end of the fifth year is $100 \%$. The mean height of residual bone (the distance between the mandibular canal and the crest of the alveolar ridge measured by $\mathrm{CBCT}$ ) was $2.76 \mathrm{~mm}$. The mean value of the marginal bone resorption was $0.309 \mathrm{~mm}$. In $20.6 \%$ of cases a positive BOP was registered.

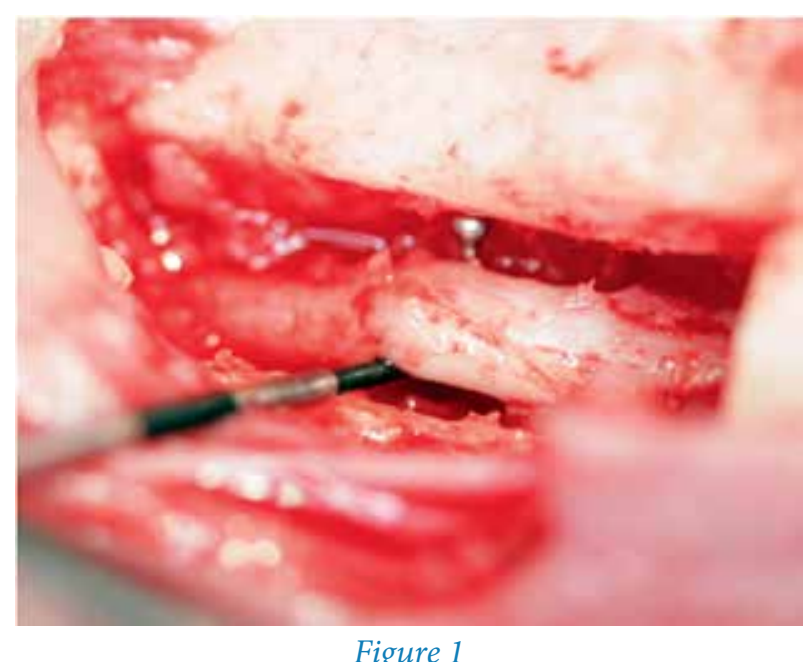

Figure 1 
Five-year follow-up of implants placed simultaneously with inferior alveolar nerve lateralisation or transposition

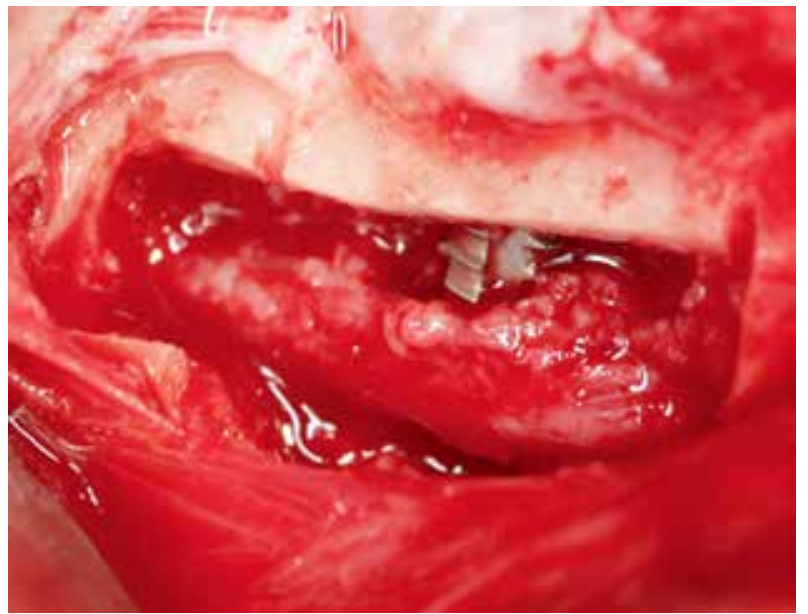

Figure 2

A positive correlation between the $\mathrm{BOP}$ and the marginal bone resorption was found.

The mean values of the marginal bone resorption were significantly higher in the registered BOP. $85.3 \%$ of the cases developed symptoms of NSD.

The mean duration of NSD was 2.06 weeks with standard deviation 1.536.

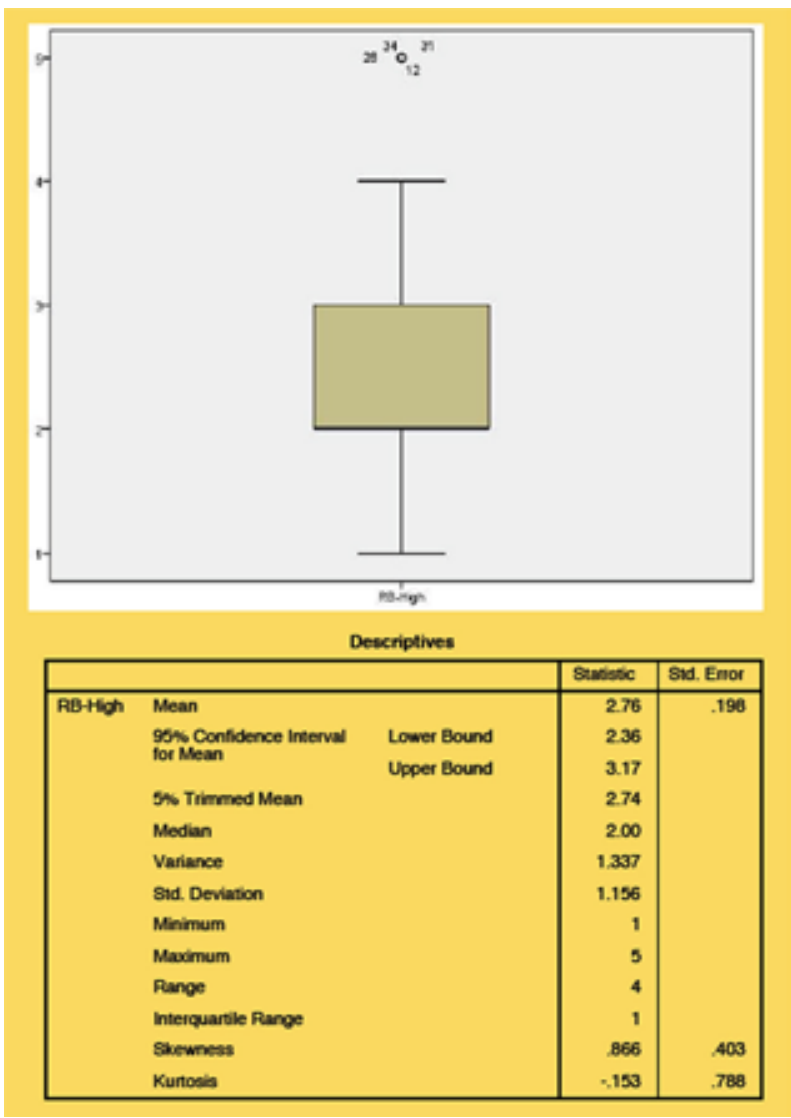

Figure 3
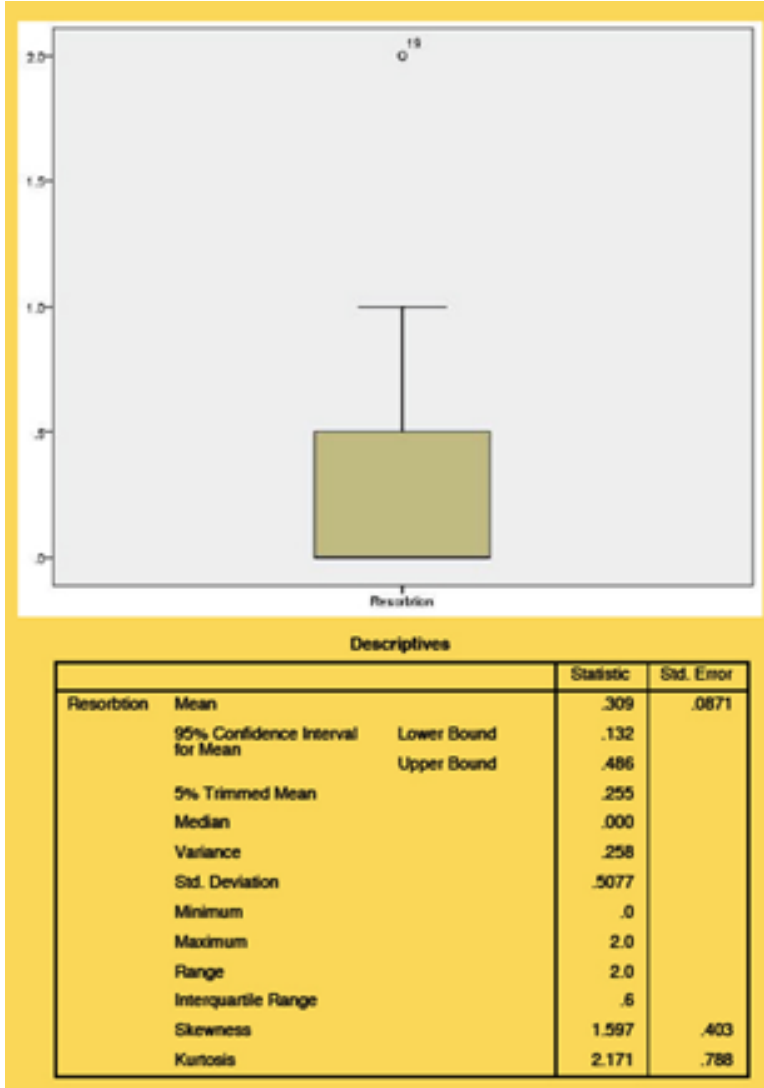

Figure 4

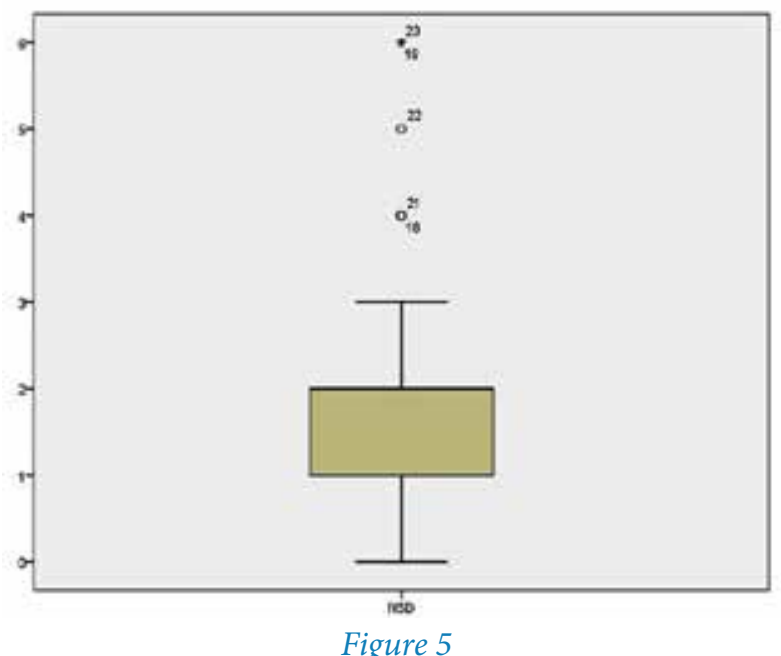

In $76.4 \%$ of patients the symptoms of NSD of nervus alveolaris inf. resolved after the second week. The maximum period of reported NSD was 6 weeks. In none of the patients was not reported lasting NSD. 


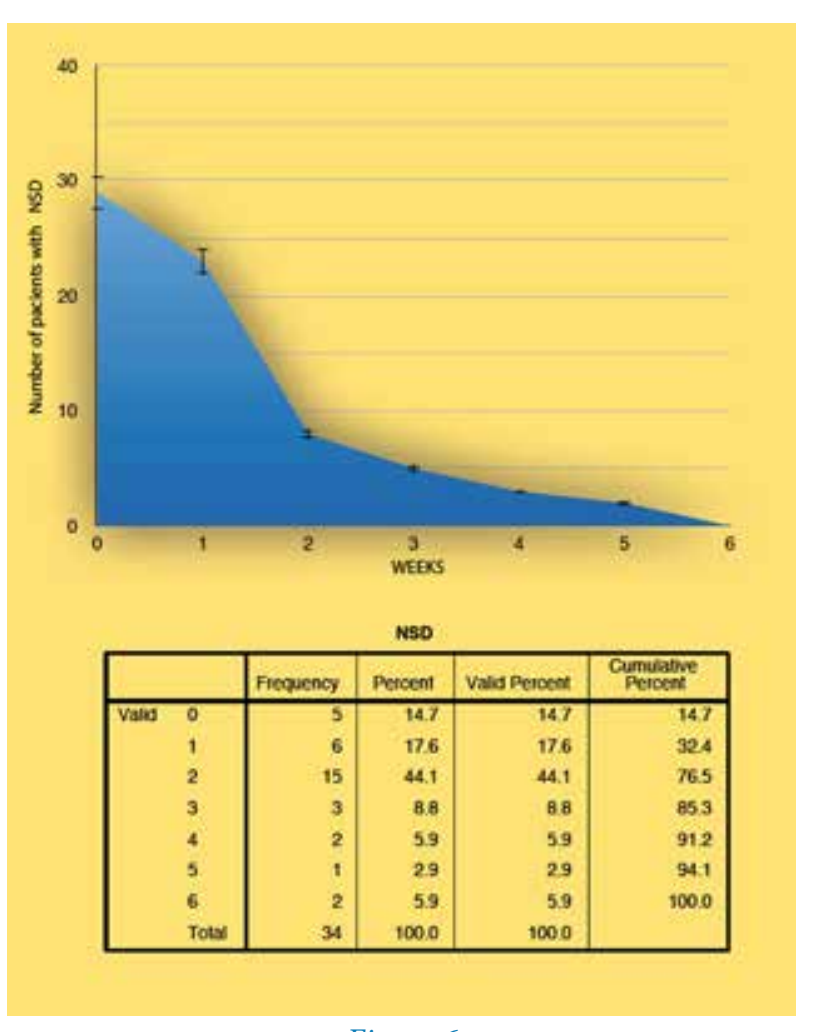

Figure 6

\section{DISCUSSION}

Lorean et al. (7) reported survival rate of the implants following a transposition of IAN $99.57 \%$; Ferrigno et al. (8) - 95.7\%; and Kan et al. (3) - 93.8\%. There are authors who reported a significantly lower survival rate of the implants placed in conjunction with the mentioned procedures Kan et al. (9) $33.33 \%$ and Karlis et al. (10) - 0\%. In terms of disturbance of neuro-sensory function of the mental nerve as a complication of these procedures Morrison et al. (described the appearance of neurosensory disorders in all patients, as in $80 \%$ of them the function normalizes after about a month, while in the remaining $20 \%$ of the cases disturbances persisted for a long period of time). The results obtained in this study in regard to survival rate shown $100 \%$ survival rate at the fifth year. With this approach the greater portion of the implant was inserted in pristine bone which a major advantage to many methods in which the implant was placed in grafted bone. Kan et al. (3) described the appearance of neurosensory disorders in $33.3 \%$ of patients who have undergone lateralization and $77.8 \%$ in patients who have undergone a transposition of the IAN. Ferrigno et al. (8) reported per- formance of 19 transpositions where in 9 cases the neurosensory function of the mental nerve recovers immediately after surgery; six patients recovered within 1 month, 2 patients - within 6 months, 1 patient receiving permanent impairment of neurosensory function. Peleg et al. (1) reported $40 \%$ immediate recovery after anesthesia, 50\% - recovery of neurosensory function upto one month and $10 \%$ - after six weeks. None of the patients did not show any lasting disruption of neurosensory function of the mental nerve. Hashemi (11) reported a violation of neurosensory function in $74 \%$ of the cases after a month out of a total 110 cases. After 6 months in only $6 \%$ of the cases the author registered disorder of the neurosensory function. Barbu et al. (12) reported a transient disorder in the neurosensory function of the mental nerve for two months. In none of the cases the authors observed no permanent damage to the neurosensory function. In a system literary analysis Abayev and Juodzbalys (13) concluded that the performance of transposition and lateralization of IAN in the majority of the cases was associated with disturbances in neuro-sensory function of the mental nerve for a period of 1 to 6 months, $99.47 \%$ of the described neurosensory complications were transient and only $0.53 \%$ of them - permanent.

\section{CONCLUSION}

The lateralization and transposition of inferior alveolar nerve are procedures with high level of complexity and require advanced experience from the surgeon. At the same time, properly performed lateralization or transposition of the lower alveolar nerve is associated with minimal risk of permanent neuro-sensory dysfunction and provides an opportunity for placement of intraosseal implants in the posterior mandible with severe atrophy at high survival rate.

\section{REFERENCES}

1. Peleg M, Mazor Z, Chaushu G, Garg AK. Lateralization of the inferior alveolar nerve with simultaneous implant placement: a modified technique. Int J Oral Maxillofac Implants. 2002 Jan-Feb;17(1):101-6.

2. Morrison A, Chiarot M, Kirby S. Mental nerve function after inferior alveolar nerve transposition for placement of dental implants. J Can Dent Assoc. 2002 Jan;68(1):46-50. 
3. Kan JY, Lozada JL, Goodacre CJ, Davis WH, Hanisch O. Endosseous implant placement in conjunction with inferior alveolar nerve transposition: an evaluation of neurosensory disturbance. Int J Oral Maxillofac Implants. 1997 Jul-Aug;12(4):463-71.

4. Khajehahmadi S, Rahpeyma A, Bidar M, Jafarzadeh $\mathrm{H}$. Vitality of intact teeth anterior to the mental foramen after inferior alveolar nerve repositioning: nerve transpositioning versus nerve lateralization. Int J Oral Maxillofac Surg. 2013 Sep;42(9):1073-8.

5. Alling CC. Lateral repositioning of inferior alveolar neurovascularbundle, Journal of Oral Surgery. 1977;35(5):article419.

6. Jensen O, Nock D. Inferior alveolar nerve repositioning in conjunction with placement of osseointegrated implants: a case report. Oral Surg Oral Med Oral Pathol. 1987 Mar;63(3):263-8.

7. Lorean A, Kablan F, Mazor Z, Mijiritsky E, Russe P, Barbu H, Levin L. Inferior alveolar nerve transposition and reposition for dental implant placement in edentulous or partially edentulous mandibles: a multicenter retrospective study. Int J Oral Maxillofac Surg. 2013 May;42(5):656-9.

8. Ferrigno N, Laureti M, Fanali S. Inferior alveolar nerve transposition in conjunction with implant placement. Int J Oral Maxillofac Implants. 2005 Jul-Aug;20(4):610-20.

9. Kan JY, Lozada JL, Boyne PJ, Goodacre CJ, Rungcharassaeng K. Mandibular fracture after endosseous implant placement in conjunction with inferior alveolar nerve transposition: a patient treatment report. Int J Oral Maxillofac Implants. 1997 Sep-Oct;12(5):655-9.

10. Karlis V, Bae RD, Glickman RS. Mandibular fracture as a complication of inferior alveolar nerve transposition and placement of endosseous implants: a case report. Implant Dent. 2003;12(3):211-6.

11. Hashemi HM. Neurosensory function following mandibular nerve lateralization for placement of implants. Int J Oral Maxillofac Surg. 2010 May;39(5):452-6.

12. Barbu HM, Levin L, Bucur MB, Comaneanu RM, Lorean A. A modified surgical technique for inferior alveolar nerve repositioning on severely atrophic mandibles: case series of 11 consecutive surgical procedures. Chirurgia (Bucur). 2014 Jan-Feb;109(1):111-6.
13. Abayev B, Juodzbalys G. Inferior Alveolar Nerve Lateralization and Transposition for Dental Implant Placement. Part I: a Systematic Review of Surgical Techniques. Journal of Oral \& Maxillofacial Research. 2015;6(1):e2. 